\title{
Circulating Filarial Antigen in the Hydrocele Fluid from Individuals Living in a Bancroftian Filariasis Area - Recife, Brazil - Detected by the Monoclonal Antibody Og4C3-assay
}

\author{
Abraham Rocha $/{ }^{+}$, Guilherme Lima*, Zulma Medeiros, Ana Aguiar-Santos, Sandra Alves, \\ Ulisses Montarroyos**, Paula Oliveira, Fátima Béliz, Maria José Netto, André Furtado***
}

\begin{abstract}
Departamento de Parasitologia, Serviço de Referência Nacional em Filariose **Núcleo de Saúde Coletiva ***Departamento de Entomologia, Serviço de Referência em Culicídeos Vetores, Centro de Pesquisas Aggeu Magalhães-Fiocruz, Av. Morais Rego s/no, Recife, PE, Brasil *Serviço de Cirurgia e Urologia, Hospital Getúlio Vargas, Recife, PE, Brasil
\end{abstract}

The purpose of this study was to examine the circulating filarial antigen (CFA) detected by the monoclonal antibody (mAb) Og4C3-ELISA in paired samples of serum and hydrocele fluid from 104 men with hydrocele, living in an endemic area of Wuchereria bancrofti. Nocturnal blood specimens were filtered and examined for microfilariae $(M F)$ and ultrasound was used in order to identify the presence of adult worms (the filaria dance sign-FDS) in the lymphatic vessels of the scrotal area. Four groups were selected according to their parasitological status: group I - $71 \mathrm{MF}$ - and FDS-; group II - $21 \mathrm{MF}+$ and FDS+; group III - $10 \mathrm{MF}$ - and FDS+ and group IV- $2 \mathrm{MF}+$ and FDS-. CFA was identified simultaneously (fluid and serum) in 11 (15.5\%), 21 (100\%), $3(30 \%)$, and 1 (50\%) in groups I, II, III, and IV, respectively. In despite of high CFA + level (antigen $\mathrm{Og} 4 \mathrm{C} 3$ ) units $/ \mathrm{ml}$, the Geometrical Mean $(G M)=2696$ ) in the sera of these 36/104 paired samples, when compared to the hydrocele fluid, $(G M=1079)$, showed a very good correlation between the CFA level in the serum and CFA level in the fluid $(r=0.731)$. CFA level in the serum of the 23 microfilaremics (groups II and IV) was extremely high $(G M=4189)$ and was correlated with MF density $(r=$ 0.442). These findings report for the first time the potential alternative use of the hydrocele fluid to investigate CFA using the $m A b$ Og4C3-ELISA.

Key words: antigen - hydrocele fluid - Wuchereria bancrofti - Og4C3 - lymphatic filariasis

Lymphatic filariasis, caused by the nematode Wuchereria bancrofti is a major public health and socio-economic problem in tropical and subtropical countries around the world. It causes economic losses and leads to great personal distress, disability, and stigmatizing diseases (Ottesen et al. 1997, Cox 2000, Haddix \& Kestler 2000).

The clinical manifestation in the endemic population is influenced by several factors: (i) the anatomic location of adult worms, (ii) the presence or absence of microfilaria, and (iii) immune responses and secondary bacterial infections (Addis \& Dreyer 2000).

More than 40 million people suffer from the chronic form of the disease (lymphoedema, elephantiasis or scrotal hydrocele) caused by this nematode (Ottesen et al. 1997). One of the chronic consequence of bancroftian filariasis in $40-50 \%$ of men living in the highly endemic areas is testicular hydrocele (Kumarasswami 2000). However, the contribution of $W$. bancrofti in the pathogenic mechanism is not well understood (Ottesen 1992).

Financial support: Papes I, 0250.250.165, Papes II, 0250.250.318/Fiocruz; Serviço de Referência Nacional em Filariose, project 268-sub-proj. 17 (Fiocruz-Fiotec-Funasa) ${ }^{+}$Corresponding author. Fax: +55-81-3453.2449. E-mail: rocha@cpqam.fiocruz.br

Received 6 August 2003

Accepted 8 December 2003
For several decades the only traditional way to diagnose the filariasis infection caused by $W$. bancrofti was by examining blood collected during the night as well as in other fluids such as hydrocele fluid and urine for the presence of microfilariae (MF) (WHO 1984, Manson-Bahr \& Bell 1987, Rocha 2000). The detection of circulating filarial antigens (CFA) (Weil et al. 1987, More \& Copeman 1990) and non-invasive imaging techniques (Amaral et al. 1994) created new alternative method in the diagnosis of bancroftian filariasis.

Ultrasound was first introduced as a new parasitological method for the identification of live adult worms of W. bancrofti, in Recife, Brazil (Amaral et al. 1994). Two years later, Norões et al. (1996) used this method to demonstrate the abnormalities in the lymphatic vessels in men with hydrocele living in endemic areas.

Two monoclonal antibodies, $\mathrm{mAb} \mathrm{Og} 4 \mathrm{C} 3$ and $\mathrm{mAb}$ AD.12 have currently been used in the detection of specific $W$. bancrofti CFA. The murine $\mathrm{mAb} \mathrm{Og} 4 \mathrm{C} 3$ is a $\mathrm{mAb}$ raised against the nematode Oncocerca gisbsoni, manufactured by TropBio ${ }^{\circledR}$ ELISA kit (TropBIO 1996). The mAb AD.12, was produced more recently by ICT Diagnostic (Australia) in a simple format card test (Weil et al. 1997). The great advantage of using CFA on the diagnosis of the infection with $W$. bancrofti is the fact that CFA levels remain the same during the $24 \mathrm{~h}$ of the day, avoiding the need to collect blood samples at night (Lammie et al. 1994). Both CFA tests using mAb $\mathrm{Og} 4 \mathrm{C} 3$ and mAb AD.12 are commercially available. Many studies have demonstrated that the CFA detected by mAbs $\mathrm{Og} 4 \mathrm{C} 3$ and $\mathrm{AD} .12$ is an indication of the active infection and markers of adult 
worms burden (More \& Coopermann 1990, Chanteau et al. 1994, McCarthy et al. 1995, Weil et al. 1996, Rocha et al. 1996).

The present study aims to evaluate how the use of hydrocele fluid could be advantageous in the diagnosis of $W$. bancrofti infection using the CFA detected by $\mathrm{mAb}$ Og4C3-ELISA.

\section{MATERIALS AND METHODS}

Patients and ethical approval - One hundred and four individuals with testicular hydrocele, living in the Metropolitan area of Recife, Brazil, were analyzed in the filariasis outpatient clinic at the Centro de Pesquisas Aggeu Magalhães (CPqAM)-Fundação Oswaldo Cruz (Fiocruz), Brazil. The study as well as the use of the biological samples from the bank of biological fluids (BBF) had approval from the ethical committees of the Hospital das Clínicas, Federal University of Pernambuco and from CPqAM. Samples were collected from 1993 to 1995 and stored at the National Reference Service of Lymphatic Filariasis at the Parasitology Department, CPqAM-Fiocruz. All parasitized individuals were treated with diethylcarbamazine (DEC), $(6 \mathrm{mg} / \mathrm{kg} / 12$ days) after collection of paired samples from sera and hydrocele fluid.

Parasitological classification - After informed consent from all individuals (and from parents of minors), the microfilaremia and adult worm carriers were diagnosed by filtration (FN) (Nucleopore, Pleasanton, CA) and Ultrasound (Amaral et al. 1994), respectively. Briefly, $1 \mathrm{ml}$ of venous blood was collected in ethylenediaminetetraacetic acid (Dennis \& Kaen 1971) at night between 11:00 PM and 01:00 AM, from each patient, was filtered through a $13-\mathrm{mm}$ polycarbonate membrane with a $3 \mu \mathrm{m}$ pore size, was stained with Carrazzi haematoxylin and examined under microscope for MF (final resolution of the $160 \mathrm{X}$ ). One week later, for criteria of amicrofilaremia, a new sample of $5 \mathrm{ml}$ of blood was collected at night and examined as described above. The remainder amicrofilaremic individuals had an additional $10 \mathrm{ml}$ of blood collected one week later. Therefore, each one of the patients considered amicrofilaremic had a total of $16 \mathrm{ml}$ of blood collected and examined (Dreyer et al. 1996a).

All individuals in this study underwent ultrasound examination of the scrotal area, using a 7.5 MHz transducer in order to look for the filarial dance sign (FDS) of adult worms in the lymphatic vessels, as described elsewhere (Amaral et al. 1994).

According to the parasitological status, the subjects were classified into four groups: (I) amicrofilaremic (MF-) and negative FDS-; (II) microfilaremic (MF+) and FDS+; (III) MF- and FDS+, and (IV) MF+ and FDS-.

Serum and hydrocele fluid - Paired samples were collected from all men with hydrocele at the same time, a day after collection of the last sample of venous blood for investigation of circulating MF. Hydrocele fluid samples were collected by needle aspiration into disposable plastic syringes from patients submitted to hydrocelectomies or at the outpatient clinic. Samples of $10 \mathrm{ml}$ from the total volume of the hydrocele fluid and $10 \mathrm{ml}$ of the venous blood from each individual were taken to be assayed. Both were centrifuged at $2000 \mathrm{rpm}$ for $5 \mathrm{~min}$ and stored in the
$\mathrm{BBF} / \mathrm{CPqAM}$ at $-20^{\circ} \mathrm{C}$ until usage in the CFA Og4C3ELISA assay.

CFA - All the samples were examined for the presence of CFA by the commercial available $\mathrm{mAb} \mathrm{Og} 4 \mathrm{C} 3$-ELISA TropBio ${ }^{\circledR}$ kit. These assays were developed according to manufacturer's instructions. The mAb Og4C3-ELISA was carried out on serum and hydrocele fluid samples, after pre-treatment by boiling, and all sera and fluid samples were tested in duplicate and the results recorded as optical density (OD). The mean OD of each sample (serum and fluid) was used to determine the response in antigen units $/ \mathrm{ml}$, from the standard curve concentrations of $O$. gibsoni antigen units/ml, according to TropBIO (1996). Samples with $\geq 32$ antigen units $/ \mathrm{ml}$ were considered positive for CFA, and samples with $\geq 32,000$ antigen units $/ \mathrm{ml}$ were assigned a fixed value of 32,000 antigen units.

Data analysis - Statistical analysis was carried out using the Student's $t$ test, in the paired samples. The Pearsons correlation coefficient with $95 \%$ confidence intervals, was calculated using the 8.0 version of the SPSS software. GM was used to compare the volumes, microfilarial density, and antigen units $/ \mathrm{ml}$.

\section{RESULTS}

Study population and parasitological profile - A total of 104 men with testicular hydrocele, aged between 16 to 73 years old (mean age 31 ); $73 \%$ ranged between 20 to 40 years of age were involved in this study. No statistical significance $(\mathrm{P}=0.780)$ was observed in the hydrocele fluid volume independently if hydrocele was uni or bilateral ( $\mathrm{GM}=47,6$ and 45,5, respectively). Unilateral hydrocele was detected in $60.6 \%$ of the patients, while $39.4 \%$ exhibit bilateral.

After the parasitological screening using FN for MF and ultrasound for FDS, the individuals were classified into four parasitologic categories: group I - 71/104 (68.2\%) MF- and FDS-; group II - 21/104 (20.1\%) MF+ and FDS+; group III - 10/104 (9.6\%) MF- and FDS+, and group IV 2/104 (1.9\%) MF+ and FDS-. Only 33 out 104 were infected. In spite of none of the 71 individuals be MF+ nor FDS+ in the group I, there was a visible lymphangectasia detected by ultra sound in 8 of them (11.3\%). In the MF+ (groups II and IV) the MF density ranged from 1 to 2260 $\mathrm{MF} / \mathrm{ml}$ blood, $(\mathrm{GM}=84,6 \mathrm{MF} / \mathrm{ml})$. Interestingly, although two individuals from group IV were MF+ (1 and $22 \mathrm{MF} /$ $\mathrm{ml}$, respectively) it was not possible to identify the FDS when ultrasound was performed in the scrotal lymphatic vessels. After filtration of $16 \mathrm{ml}$ of the total volume of venous blood, collected at three different periods, all individuals from group III were considered "amicrofilaremic adult worm carriers" as described elsewhere (Dreyer et al. 1996).

CFA test - All MF+, but one, presented high levels of $\mathrm{CFA}+$ in serum as well as in fluid, and what calls attention is that CFA+ was detected in the fluid of 37 (35.57\%) subjects from which 15 were MF-.

Thus, simultaneously in serum and fluid samples CFA+ was detected in $36(92.3 \%)$ out of 39 individuals. CFA+ units $/ \mathrm{ml}$ in the serum $(\mathrm{GM}=2696)$ were statistically more significant $(P<0.001)$ than the CFA units/ml in the fluid $(\mathrm{GM}=1079$. On the order hand, it is important to emphasise 
that despite of the fact that the CFA+ level in the serum was two times higher than in the fluid, there is a positive correlation between the samples $(r=0.731)$, i.e. there was a very good correlation in the levels of CFA units in the serum and in the hydrocele fluid (Figure). Two individuals (group I) were CFA+ only in the serum with 112 and 1952 CFA units/ml, and one (group III) only in the fluid (424 CFA units/ml). In the $23 \mathrm{MF}+$ (groups II and IV) the intensity of CFA+ level of the serum was extremely high $(\mathrm{GM}=4189)$ and correlated with MF density $(\mathrm{r}=.442$; $P=.004)$.

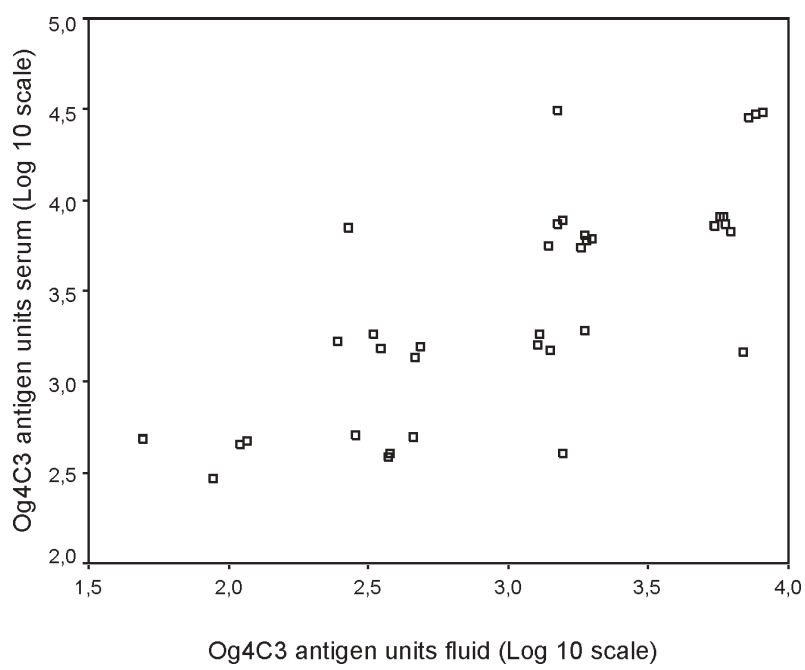

Relation between circulating filarial antigen units from sera and hydrocele fluid samples in the 36 positive paired individuals.

\section{DISCUSSION}

In the past seven decades many researchers have been interested in utilizing the hydrocele fluid to obtain and isolate CFA from $W$. bancrofti. The use of the hydrocele fluid became a tool of value in diagnosing individuals with $W$. bancrofti infection due to the straight-forward procedure to obtain fluid in ambulatory punctions or in the hydrocelectomies (Acton \& Rao 1933, Malhotra et al. 1985, Ramaprasad \& Harinath 1989, Singh et al. 1993). Recently, the availability of monoclonal antibodies Og4C3
(More \& Cooperman 1990) and AD.12 (Weill et al. 1997) which can be used in ELISA and immunochromatography, respectively, have become important for filariasis diagnosis in biological fluids. Hassan et al. (1996) using the mAb AD.12-ELISA were able to identify CFA from paired samples of sera and hydrocele fluids in $50 \%$ and $66.7 \%$ of the $\mathrm{MF}$ - and $\mathrm{MF}+$ men with hydrocele, respectively. However, the results showed here demonstrate that the mAb Og4C3-ELISA can also be used as a diagnostic tool in filariasis, since through this technique CFA was detected in $58.1 \%$ of the MF-. This fact must be taken in consideration mainly by those liable for filariasis control programs.

One of the individuals belonging to group III had the hydrocele fluid collected from a site adjacent to the area containing adult worms. This individual was CFA+ just in the hydrocele fluid. Two individuals from group I were $\mathrm{CFA}+$ only in the sera. At the clinical evaluation it was showed that these individuals had clinical hydrocele for more than 10 years. Therefore, it is possible that the adult worms died leaving low levels of circulating CFA, which could not be detected in the hydrocele fluid. The absence of CFA in serum and hydrocele fluid in some infected individuals remains unclear.

Data from the National Reference Service of Lymphatic Filariasis have demonstrated that $40 \%$ of individuals treated with a single dose of $6 \mathrm{mg} / \mathrm{kg}$ of DEC, after the FDS disappearance, remained CFA + for 48 months (Rocha, data not published). The sensitivity of CFA from MF+ and $\mathrm{MF}$ - individuals was similar to our previous data using serum samples of $\mathrm{MF}+, \mathrm{MF}-$ and $\mathrm{FDS}+$ related to various densities of MF (Rocha et al. 1996).

Studies from More and Cooperman (1990), Chanteau et al. (1994), and Lalitha et al. (1998), concluded that the $\mathrm{mAb} \mathrm{Og} 4 \mathrm{C} 3$ detects CFA from adult worms, excluding the contribution of MF in the production of CFA. Many studies (including this article), do not agree with this hypothesis (Rocha et al. 1996, Nicolas et al. 1997, Itoh et al. 1999). These authors demonstrated on the contrary that the CFA intensity is directly proportional to the microfilaremia density, i.e., the higher the MF density, the higher the CFA levels.

Infected patients treated with high doses of ivermectin, became MF- for a period of one year, but they were still FDS carriers. These individuals which were monitored by

TABLE

Characteristics of the groups according to the parasitological status and circulating filarial antigens (CFA) by Og4C3-ELISA, CFA level in the samples of serum, and hydrocele fluid

\begin{tabular}{|c|c|c|c|c|c|c|c|}
\hline $\begin{array}{l}\text { Parasitologic } \\
\text { groups }\end{array}$ & $n$ & $\%$ & $n$ & $\begin{array}{c}\text { CFA Og4C3 } \\
\text { unit serum }{ }^{b} \\
\text { GM (range) }\end{array}$ & $n$ & $\begin{array}{c}\text { CFAOg4C3 unit } \\
\text { fluid }^{b} \\
\text { GM (range) }\end{array}$ & $\begin{array}{c}\text { Positive } \\
\text { paired } \\
\text { samples }\end{array}$ \\
\hline Group I (MF- and FDS-) & 71 & 68.2 & 13 & $1080(290-5583)$ & 11 & $448(49-6867)$ & 11 \\
\hline Group II (MF+ and FDS+) & 21 & 20.1 & 21 & $4420(389-31083)$ & 21 & $1644(110-8090)$ & 21 \\
\hline Group III (MF- and FDS +) & 10 & 9.6 & 3 & 3044 (499-29597) & 4 & $1870(456-7676)$ & 3 \\
\hline Group IV (MF + and FDS-) & 2 & 1.9 & 1 & 1354 & 1 & 465 & 1 \\
\hline Total & 104 & 100 & 39 & $2696(112-31083)$ & 37 & $1079(49-8090)$ & 36 \\
\hline
\end{tabular}

$a$ : parasitologic status was defined on the basis of the microfilaremia (MF+) and amicrofilaremia (MF-) and filarial dance sign (FDS), presence (FDS+) and absence (FDS-); $b$ : data are geometric mean (GM) units 
ultrasound for a year (Dreyer et al. 1996b) had a significant reduction in the CFA levels, when compared to the pre-treatment period, but they did not become negative (Rocha, data not published).

The mechanism by which ivermectin acts on $W$. bancrofti adult worms is still unknown. However, studies by Schulz-Key and co-workers $(1985,1986)$ involving infected individuals with $O$. volvulus and treated with ivermectin have demonstrated that the production of MF from the uterus of female adult worms was inhibited, even though the embryogenesis was not affected. Thus, it is possible that the ivermectin mechanism observed with $O$. volvulus is similar to the one observed with $W$. bancrofti female adult worms. Therefore, the absence of MF in the circulation caused by the inhibition of parturition, its limited reproduction (low or ultra-low microfilaremia) or the infection by only one gender will affect the CFA concentration, leading to false negative results (Rocha et al. 1996). These findings suggest that MF may strongly contribute to the CFA production, or at least that the majority of the CFA is produced during parturition, with the secretion of products from the uterus of female adult worms which are recognized by the $\mathrm{mAb} \mathrm{Og} 4 \mathrm{C} 3$.

Although MF and FDS were not detected in 71 out of $104(68.2 \%)$ individuals from group I, 8/71 (11.3\%) individuals presented linfangectasia and 13/71 (18.3\%) were CFA+. Therefore, it is possible that adult worm contributes in the triggering process of the clinical form of hydrocele (Norões et al. 1996, Dreyer et al. 2002), since the CFA+ individuals presented linfangectasia and lived in endemic areas which are an indication of filarial infection (Dreyer et al. 1996, Rocha 2000). Considering this hypothesis as a starting point, and summing up all the truly infected individuals bearing MF, FDS, CFA+ and linfangectasia, we would have 54 out of $104(51.9 \%)$ which possibly had W. bancrofti as the ethiology of clinical hydrocele.

Studies have demonstrated that the primary pathologic lesion of the infection caused by $W$. bancrofti is the lymphatic dilation (Dreyer et al. 2002). The linfangectasia is progressive and it is not yet known if this is caused by the secretion of chemical substances from adult worms or if the parasite induces the host to produce vasodilators. Thus, it is of extreme importance to diagnose this parasitosis as early as possible, to avoid the development of more debilitating forms. Our results showed the possibility to use the hydrocele fluid in order to enhance the diagnosis of individuals bearing the $W$. bancrofti infection.

Moreover, both sera and fluid samples from the 22 out of $23 \mathrm{MF}+$ individuals (group II and $I V$ ) were positive using the mAb AD.12 assay (ICT card test, BINAX, Inc.) (Rocha, data not published). These data are of great interest, since the hydrocele fluid collected during the emptying of the scrotal area is always discarded in both ambulatory procedures and hydrocelectomies. The finding that 95.6\% of microfilaremic individuals have CFA+ in hydrocele fluid could help in the quick diagnosis and treatment of the infection. The fluids can be used in the ICT-card test, and the results can be obtained in just $10 \mathrm{~min}$. In case of a positive result, infected individuals could be pre- scribed an immediate treatment with DEC to avoid progression of disease.

\section{ACKNOWLEDGEMENTS}

To Dr David Addis for the critical review of the manuscript and helpful comments.

\section{REFERENCES}

Acton HW, Rao SS 1933. The pathology of elephantiasis of filarial origin. Ind Medic Gazette 68: 305-314.

Addis D, Dreyer G 2000. Treatment of lymphatic filariasis. In TB Nutman, Lymphatic Filariasis, Imperial College Press, London, chap. 5, p. 103-125.

Amaral F, Dreyer G, Figueredo-Silva J, Norões, Cavalcanti A, Samico SC, Santos A, Coutinho A 1994. Live adult worms detected by ultrasonography in human bancroftian filariasis. Am J Trop Med Hyg 50: 753-757.

Chanteau S, Moulia-Pelat JP, Glaziou P, Nguyen NL, Luquiaud P, Plichart C, Martin PMV, Cartel JL 1994. Og4C3 circulating antigen: a marker of infection and adult worm burden in Wuchereria bancrofti filariasis. J Infec Dis 170: 247-250.

Cox FEG 2000. Elimination of lymphatic filariasis as a public health problem. Parasitol Today 4: 135-137.

Dennis DT, Kaen BH 1971. Isolation of microfilariae: report of new method. J Parasitol 57: 1146-1147.

Dreyer G, Addiss D, Norões J, Amaral F, Rocha A, Coutinho A 1996b. Ultrasonographic assessment of the adulticidal efficacy of repeat high-dose ivermectin in bancroftian filariasis. Trop Med Int Health 1: 427-432.

Dreyer G, Addiss D, Roberts J, Norões J 2002. Progression of lymphatic vessel dilation in presence of living adult Wuchereria bancrofti. Trans R Soc Trop Med Hyg 96: 157161.

Dreyer G, Santos A, Norões J, Rocha A, Addis D 1996a. Amicrofilaraemic carriers of adult Wuchereria bancrofti. Trans $R$ Soc Trop Med Hyg 90: 288-289.

Hassan MM, Ata M, Ramzy RMR, El-Gendi AEMA, Hegab MHA, Sh. Gabr N, EL-Chourbagy, Mostafa AA, Naguib AMI 1996. Evaluating the detection of circulating filarial antigen in diagnosis of bancroftian filariasis and filarial hydrocele. J Egypt Soc Parasitol 26: 687-696.

Itoh M, Weerasooriya MV, Gunawardena NK, Mudalige MPS, Samarawickrema WA, Kimura E 1999. Wuchereria bancrofti antigenemia in Sri Lanka. Trop Med Int Health 4: 207-210.

Kumaraswami V 2000. The clinical manifestations of lymphatic filariasis. In TB Nutman, Lymphatic Filariasis, Imperial College Press, London, chap. 5, p. 103-125.

Lalitha P, Ravichandran M, Suba S, Kaliraj P, Narayanan RB, Jayaraman K 1998. Quantitative assessment of circulating antigens in human lymphatic filariasis: a field evaluation of monoclonal antibody-based ELISA using blood collected on filter strips. Trop Med Int Health 3: 41-45.

Lammie PJ, Hightower AW, Eberhard ML 1994. The age-specific prevalence of antigenemia in a Wuchereria bancroftiexposed population. Am J Trop Med Hyg 51: 348-355,

Malhotra A, Prassad GBKS, Harinath BC 1985. Detection and isolation of filarial antigens from hydrocoele fluid and its use in diagnosis. Indian J Exper Biol 23: 180-182.

Manson-Bahr PEC, Bell DR 1987. Examination of blood for presence of microfilariae. Mansons Trop Dis 19: 1494.

McCarthy JS, Guinea A, Weil GJ, Ottesen EA 1995. Clearance of circulating filarial antigen as a measure of the macrofilaricidal activity of diethylcarbamazine in Wuchereria bancrofti infection. J Infec Dis 172: 521-526.

More SJ, Copeman DB 1990. A highly specific and sensitive 
monoclonal antibody-based ELISA for the detection of circulating antigen in bancroftian filariasis. Trop Med Parasitol 41: 403-406.

Nicolas L, Plichart C, Nguyen LN, Molia-Pelat J 1997. Reduction of Wuchereria bancrofti adult worm circulating antigen after annual treatments of diethylcarbamazine combined with ivermectin in French Polynesia. J Infect Dis 175: 489492.

Norões J, Addiss D, Santos A, Medeiros Z, Coutinho A, Dreyer G 1996. Ultrasonographic evidence of abnormal lymphatic vessels in young men with adult Wuchereria bancrofti infection in the scrotal area. J Urol 156: 409-412.

Ottesen EA 1992. Infection and disease in lymphatic filariasis: an immunological perspective. Parasitology (Suppl.) 104: S71.

Ottesen EA, Duke BOL, Karam M, Behbehai K 1997. Strategies and tools for the control/elimination of lymphatic filariasis. Bull WHO 6: 491-503.

Ramaprasad P, Harinath BC 1989. Fraction, characterization and diagnostic potencial of filarial antigens isolated from hydrocoele fluid in bancroftian filariasis. Trans $R$ Soc Trop Med Hyg 83: 90-94.

Rocha A 2000. Available laboratory diagnostic methods of lymphatic filariasis. Rev Bras Anal Clin 32: 265-270.

Rocha A, Addiss D, Ribeiro ME, Norões J, Baliza M, Medeiros Z, Dreyer G 1996. Evaluation of the OG4C3 ELISA in Wuchereria bancrofti infection: infected persons with undetectable or ultra-low microfilarial densities. Trop Med Int Health 1: 859-864.

Schulz-Key H, Greene BM, Awadzi K, Larivière M, Klager S,
Dadzie Y, Aziz MA 1985. Efficacy of ivermectin on the reproductivity of female Onchocerca volvulus. Trop Med Parasitol 37: 89.

Schulz-Key H, Klager S, Awadzi K, Diallo S, Greene BM, Larivière-Aziz MA 1986. Treatment of human onchocerciasis: The efficacy of ivermectin on the parasite. Trop Med Parasitol 36: 20

Singh TA, Cheirmaraj K, Reddy MVR, Narang R, Harinath BC 1993. Diagnostic use of filarial antibody and antigen isolated from hydrocele fluid for human filariasis. Indian J Exp Biol 31: 1-4.

TropBIO 1996. ELISA kit for detecting and quantifying Wuchereria bancrofti antigen. Townsville, Australia, JCU Tropical Biotecnology Pty, James Cook University of North Queensland.

Weil GJ, Jain DC, Santhanam S, Malhotra A, Kumar H, Sethumadhavan KVP, Lifftis F, Ghosh TK 1987. A monoclonal antibody-based enzyme immunoassay for detecting parasite antigenemia in bancroftian filariasis. $J$ Infect Dis 156: 350-355.

Weil GJ, Lammie PJ, Weiss N 1997. The ICT filariasis test: a rapid-format antigen test for diagnosis of bancroftian filariasis. Parasitol Today 13: 401-404.

Weil GJ, Ramzy RMR, Chandrashekar R, Gad AM, Lowrie RC, Faris R 1996. Parasite antigenemia without microfilaremia in bancroftian filariasis. Am J Trop Med Hyg 55: 333-337.

WHO-World Health Organization 1984. Lymphatic filariasis fourth report of the WHO expert committee on filariasis. WHO technical reports series 702 . 